\section{¿Hedonistas o revolucionarios? \\ Política homosexual radical e izquierda trotskista en Argentina y Brasil (1967-1983)}

Santiago Joaquín Insausti

UBA-CONICET

\section{Resumen}

El fracaso que el Frente de Liberación Homosexual argentino experimenta en sus intentos de aliarse con la izquierda partidaria en los setenta contrasta con la rápida y sinérgica articulación con el trotskismo que el movimiento homosexual logra en Brasil. Este trabajo analizará las políticas de alianzas del Frente argentino y de la Facción Homosexual de Convergencia Socialista brasilera estudiando su interrelación con las políticas de género y sexualidad que desarrolló la izquierda, las diferentes etapas por las que atravesaban los aparatos represivos en cada país, las conexiones transnacionales entre organizaciones y los momentos de la izquierda a nivel global. Se analizará en particular el rol del trotskismo, el cual ofreció mayores oportunidades coyunturales de alianza con los homosexuales que otras corrientes del movimiento obrero. La investigación se basará en el análisis de un corpus documental diverso, que incluye fuentes personales de algunos de los activistas y entrevistas personales en profundidad.

\footnotetext{
Abstract

In the seventies, the Argentine Frente de Liberación Homosexual failed in its attempts to become an ally of left-wing parties, while comparatively, the Brazilian homosexual movement achieved a fast and synergic integration with Troskyist forces. Through an analysis of a diverse body of primary sources, including personal records and in-depth interviews, this article will explore the history of the Argentine Frente and the brazilian Facción Homosexual de Convergencia Socialista. The focus will be on
}

\section{Palabras Clave}

Frentes de Liberación Homosexual, Historia de la izquierda y del movimiento obrero, historia de la sexualidad, Pasado queer, Latinoamerica, Siglo XX

Keywords

Gay Liberation Fronts, Left-wing organizations, labor movement, queer past, Latin america, Twentieth century. 
the alliances these groups tried to build with left-wing parties, a topic examined in the context of the politics of gender and sexuality within the left and in relation to the different stages of state violence and persecution of political dissidence deployed in each country in different moments. The article will also discuss the international networks developed by the homosexual movement and the global history of the left. The role of Trotskyism is discussed in more detail because this political current offered more alliance opportunities to homosexual movements in several countries.

\section{Introducción}

Algunos años antes de devenir el principal referente del Frente de Liberación Homosexual y siendo apenas un adolescente, Néstor Perlongher se había iniciado en la militancia en Política Obrera, una organización trotskista con fuerte trabajo territorial.

La primera prioridad de esta organización -de fuerte tendencia obrerista, como la mayoría de las orgas de la época- era insertarse en las fábricas a través de la proletarización de sus militantes. En este marco, la actividad más importante consistía en volantear en los cordones industriales del Gran Buenos Aires, debatiendo con los trabajadores e involucrándose en los conflictos obreros. En 1967, en plena dictadura militar, esta militancia clandestina implicaba mucha exposición y riesgo. Imaginemos a estudiantes de indisimulable clase media interceptando a los obreros al ingreso de las fábricas, aun en las penumbras de la madrugada en la desolación de la zona industrial de Avellaneda, al tiempo que intentaban pasar desapercibidos ante la mirada de la policía y de los capataces.

Perlongher, quien ya empezaba a plantear la necesidad de que el partido abrace la causa homosexual, genera rápidamente tensiones en la organización. Según Roberto Gramar (2017), su responsable político y compañero de activismo, "Néstor no solo consideraba que la reivindicación de la liberación homosexual era fundamental: buscaba, además, exhibir su condición de un modo transgresor, exponiéndose a sí mismo y a la organización a situaciones represivas." Estas tensiones determinaron la partida de Perlongher, quien pocos años después devendría uno de los más importantes cuadros intelectuales de la revolución sexual, y propondría ver en la marica y en la práctica escandalosa del mariconeo no una debilidad sino una potencia inconfrontable para derrumbar el patriarcado y por su intermedio el capitalismo.

Décadas después, participé de algunas discusiones con viejos activistas, tanto troskos como homosexuales, sobre la compatibilidad entre la política del loqueo -que había caracterizado la militancia homosexual de los setentas-y el trabajo territorial de base de las organizaciones de izquierda. Nos imaginamos a Perlongher performando las poses de la loca, conjurando las formas del mariconeo: vestido de colores vivos, lleno de accesorios y pañuelitos. Quizá correteando y dando grititos entre los obreros que hacían fila para ingresar a la fábrica, para pánico de sus compañeros de militancia. ¿Fue homofóbico el planteo de Palabra Obrera? ¿Eran el mariconeo y el escándalo performances validas en la lucha revolucionaria? ¿Ponían de verdad estas prácticas en peligro el trabajo territorial?

Las décadas del sesenta y setenta son momentos de rápidas transformaciones. La emergencia de la juventud como nuevo sujeto social, la revolución sexual, las nuevas formas de la militancia de izquierda que rompían con el mundo del este demarcaban un terreno de experimentación política en la cual todo lo dado era propenso de ser cuestionado y reconstruido. En este marco, aunque en diferentes momentos, la 
izquierda brasilera y argentina se topan con la emergencia del movimiento homosexual y con la exigencia de sus facciones más radicalizadas de ser consideradas agentes de la revolución. Las reacciones, en ambos países, serán diferentes.

El Frente de Liberación Homosexual (FLH) surge en Argentina a principios de la década del setenta, nutrido por el marxismo e influenciado por un conjunto heterogéneo de teorizaciones ligadas a la nueva izquierda global del período que incluían ciertas variantes del freudo-marxismo, del feminismo radical y de la producción de algunos movimientos sociales estadounidenses, como los black panthers. Su principal antagonista, serán los aparatos represivos del estado. Desde mediados de la década del cuarenta y hasta entrados los ochentas, una parte importante de la vida de los homosexuales argentinos -y latinoamericanos- transcurría en prisión a causa de una serie de dispositivos para-judiciales -los edictos policiales- que penalizaban su tránsito por el espacio público.

En la lucha contra la represión y el marco de la radicalización política de la época, conceptualizarán la revolución sexual como indisociable de la revolución social, y apostarán a una alianza con las organizaciones de izquierda. Sin embargo, el rechazo de estas y la exacerbación de la represión agotan estas tentativas.

Mientras los militantes del FLH fracasan en sus esfuerzos de intentar una alianza con las organizaciones de izquierda, la experiencia brasileña es diferente. Surgido apenas dos años después, el grupo brasileño "Somos" logra una rápida y sinérgica articulación con estos sectores políticos al tiempo que algunas agrupaciones radicales y del movimiento de trabajadores se involucran tempranamente en la militancia homosexual. Por ejemplo, miembros de la organización trotskista Convergencia Socialista (CS), participan activamente del movimiento de diversidad sexual, y en 1979 organizan su propia agrupación al interior del partido, la "Facción Homosexual de Convergencia Socialista" (FHCS).

Contrariamente a lo esperado, en Brasil el rechazo a esta alianza no provendría de los partidos de izquierda, como en la Argentina, sino de los sectores reformistas del propio movimiento homosexual. De modo tal que la discusión entre las perspectivas radicales y las posiciones autonomistas signan al movimiento homosexual brasilero del período, al mismo tiempo que el acceso de los homosexuales al aparato partidario trotskista le da a la dinámica del movimiento un discurso y una impronta distintiva.

Como desarrollaré, el movimiento homosexual brasileño se pensaba en continuidad con el FLH. Paralelamente, Convergencia Socialista, estaba en intima conexión con el Partido Socialista de los Trabajadores (PST) argentino, que había rechazado incorporar las demandas de los homosexuales muy poco tiempo antes. La principal pregunta qué hilvanará este trabajo será por qué espacios políticos tan semejantes reaccionaron con tan poco tiempo de diferencia de modo tan diferente a la interpelación que recibían por parte de los colectivos de diversidad sexual.

Los estudios sobre el movimiento homosexual generalmente han enfatizado los factores ideológicos internos a las agrupaciones y desatendido el estudio de los contextos políticos que finalmente determinan el diseño y la viabilidad de determinadas agendas. Muchas veces, el éxito de una táctica política puede tener más que ver con las oportunidades que se generan en un marco político concreto que con los posicionamientos teóricos abstractos de determinados grupos.

En el caso del FLH y de Somos, tanto las dinámicas de la articulación con la izquierda -de la cual ambas organizaciones se consideraban parte-como las diferentes etapas 
en los aparatos represivos del estado y los diálogos internacionales y los diferentes momentos de la izquierda global son cruciales para entender su desarrollo.

En este marco, nuestra hipótesis será que, en el caso de los frentes de liberación homosexual latinoamericanos -y especialmente en los casos argentino y brasilero en los cuales nos enfocaremos especialmente en ese trabajo- las políticas diseñadas y el éxito o fracaso de las mismas no pueden entenderse si no es en el entrecruzamiento de tres dimensiones. En primer lugar, en relación a las estrategias que diseñaban en pos de asociarse -con mayor o menor éxito- a la izquierda partidaria. En segundo lugar, en relación a las variaciones de las políticas de género y la sexualidad de las organizaciones, las cuales devenían en obstáculos o facilitadores para la incorporación de los homosexuales a su proyecto político. Finalmente, a los diferentes momentos de los estados autoritarios que podían habilitar-o no- el espacio para el surgimiento de esta alianza.

En una primera parte, describiré cómo los cambios en la coyuntura política argentina generan diferentes estrategias por parte del FLH en su proyecto de asociarse con la izquierda revolucionaria. En una segunda, describiré las tensiones con respecto a la sexualidad al interior del campo profundamente heterogéneo de la izquierda latinoamericana y cómo ciertas tradiciones y posicionamientos se convirtieron en obstáculos o en facilitadores para la incorporación de las agendas homosexuales. En tercer lugar, analizaré la experiencia en Brasil de la Facción Homosexual de Convergencia Socialista y describiré como enfrento tanto la orientación del movimiento homosexual hacia una perspectiva radical como el trabajo contra la homofobia al interior del partido. Finalmente, a modo de conclusión, esbozaré una interpretación acerca de cómo las diferencias en los contextos políticos y en el momento global de las izquierdas permiten aportar datos para pensar cómo proyectos políticos tan semejantes obtienen resultados tan disímiles con tan pocos años de diferencia.

La investigación se basará en el análisis de un corpus documental diverso. La reconstrucción del FLH se asienta en los hallazgos de trabajos anteriores del autor (Insausti, 2007; 2019; Ben e Insausti, 2017), en el análisis de bibliografía secundaria (Sebreli, 1997; Rapisardi y Modarelli, 2001; Simonetto, 2017; Vespucci, 2011, 2017) y de documentos internos de las organizaciones y en una serie de entrevistas realizadas a los ex activistas del frente Zelmar Acevedo, Marcelo Benítez, Héctor Anabitarte y Sergio Pérez Álvarez. El análisis -aún exploratorio- del caso brasilero se basará en el estudio de bibliografía secundaria y en un análisis preliminar de los documentos organizacionales. ${ }^{1}$ posible gracias a que mi proyecto fue favorecido con la Phil Zwickler Memorial Research Grant, otorgada por la Cornell University Library's Human Sexuality Collection y con la Wallis Annenberg Research Grant otorgada por la University of Southern California. Agradezco especialmente al Dr. James Green el haberme permitido el acceso a su invaluable archivo. Este trabajo forma parte del proyecto

"Diversidad de género, masculinidad y cultura en España, Argentina y México" (FEM2015-69863-P MINECOFEDER) del Ministerio de Economía y Competitividad de España y del Proyecto "Perspectivas teóricometodológicas sobre política, género, sexualidad y salud en América Latina" (UBACYT 20020130100486) de la Universidad de Buenos Aires y fue realizado en el marco de una estancia posdoctoral en la Facultad de Filosofía y Letras de la misma universidad.

\section{El Frente de Liberación Homosexual argentino}

La historia del movimiento de liberación homosexual argentino en los sesentas y setentas puede pensarse dividida en tres períodos (Insausti, 2019). Un primer momento de vinculaciones con el ámbito sindical (1967-1971), un segundo momento caracterizado por el intento obsesivo de articular estrategias políticas con las organizaciones de izquierda (1971-1974) y en el cual nos enfocaremos principalmente en este trabajo $\mathrm{y}$, fracasado este, un tercer momento de repliegue hacia la construcción interna y de emergencia del discurso identitario (1974-1976).

"Nuestro Mundo", la primera organización de homosexuales latinoamericanos surge durante los primeros años de la Revolución Argentina en Gerli, un suburbio obrero del conurbano bonaerense. Este grupo, estaba compuesto mayoritariamente por obreros, sindicalistas y migrantes de las provincias del norte argentino, históricamente las más 
pobres de la Argentina. El grupo -liderado por Héctor Anabitarte, un dirigente sindical y cuadro del Partido Comunista- surge como un desprendimiento del FOECYT, el sindicato de Correos y Telecomunicaciones. Estos primeros activistas no tendrán gran formación teórica y su accionar será acotado.

En 1971, los activistas de "Nuestro Mundo" entrarán en contacto con un núcleo de prestigiosos escritores y ensayistas -entre los que estaban Juan José Sebreli, Blas Matamoros y Juan José Hernández- que tenían tradición de lecturas de izquierda y que ya habían estado en contacto con los movimientos de liberación norteamericanos, lo que les permite reestructurar su interpretación de la homosexualidad y la militancia. Sebreli (1964) acababa de publicar su best-seller Buenos Aires, vida cotidiana y alienación, el cual, como el mismo señala en el prólogo de su segunda edición (2003), era fruto del clima intelectual de fines de los cincuenta y principios de los sesentas profundamente influenciado por el marxismo, luego de la publicación de los Grundrisse, la revalorización de Hegel, el redescubrimiento de autores como Lukács, Korsh y Gramsci y la revelación de la escuela de Frankfurt. A partir de ese momento la opresión sexual será conceptualizada como indisociablemente ligada a la opresión social, y la posibilidad de la liberación dependerá necesariamente de la alianza con el resto de los movimientos sociales en lucha. Del contacto entre los sindicalistas de "Nuestro Mundo" y estos intelectuales -que se nuclearán en el grupo "Profesionales"surgirá el Frente de Liberación Homosexual.

En 1972, el frente crecerá por la incorporación de activistas que se sumarán a participar en diferentes grupos. Entre ellos, el grupo Eros, formado por estudiantes de Filosofía y Letras y liderado por Néstor Perlongher, que contaba con una breve experiencia en el activismo trotskista. Eros, aportará una lectura original de la opresión sexual, también afianzada en la lectura de los clásicos del marxismo, pero sobretodo profundamente influenciada por el freudomarxismo de autores como Herbert Marcuse (1955). La radicalidad de estos jóvenes acostumbrados a debates furibundos en asambleas universitarias entrará muy rápidamente en conflicto con la mesura de los escritores reunidos en el "Grupo profesionales".

A partir de estas nuevas incorporaciones, y en el contexto de la intensificación de la protesta social y del entusiasmo de los sectores progresistas con las organizaciones armadas, el FLH se radicalizará y empezará a tender puentes en vías de aliarse con las diferentes organizaciones de la izquierda. El 24 de agosto de 1972 -solo dos días después de la masacre de Trelew-, darán la primera entrevista a un medio masivo de comunicación, ${ }^{2}$ en la cual se presentarán como un grupo guerrillero, siguiendo todos los clichés que la representación de los medios masivos de comunicación hacía de ellos. En la nota, por ejemplo, los entrevistados sostienen "tener una organización similar a la de los grupos guerrilleros" basada en "grupos celulares, columnas y un Presidium Supremo" 3 y se ilustra con una foto de dos personas encapuchadas con el puño en alto frente a un estandarte con las siglas de la organización. Si bien la performance fue montada en concomitancia con la prensa (Sebreli, 2003) y el FLH nunca evaluó seriamente comprometerse con la lucha armada, el montaje fotográfico y la línea política planteada en la nota dan cuenta por un lado de un intento de capitalizar la atención puesta en la figura del combatiente tras la fuga del Penal de Rawson unos pocos días antes. Pero por otro, también habla de un intento de acercamiento a las organizaciones armadas, producto quizá de una identificación genuina con la figura del guerrillero en el marco de una generación profundamente impactada por la revolución cubana.

El año siguiente -1973- es el año de mayor actividad militante del frente, en coincidencia con el revés del régimen autoritario del General Lanusse que marca la derrota de la Revolución Argentina y la asunción del gobierno progresista de Héctor Cámpora,
2. "Homosexualidad: las voces clandestinas", Panorama, 24 de Agosto de 1972.

3. En referencia al Presidium del Soviet Supremo, uno de los principales órganos de gobierno de la URSS. 
4. "Homosexualidad: ¿Quiénes son?", Panorama, 2 de mayo de 1974.

5. "La batalla homosexual en Argentina”, Así, 3 de julio de 1973.

6. "La batalla homosexual en Argentina", Así, 3 de julio de 1973.

7. "Cerremos filas", Así, 21 de junio de 1973.

8. Frente de Liberación Homosexual, Homosexuales, julio de 1973.

\footnotetext{
9. "Letter from Argentina", Body
} Politics, septiembre de 1973 . que suspende momentáneamente la persecución a los militantes populares. En ese año, el inminente retorno del exilio de Perón, que cohesionaba a la mayoría del campo popular, motiva un rediseño de las estrategias del frente, que dedica todas sus fuerzas a incorporarse a este campo de organizaciones mediante una reivindicación de la figura de Perón, en un intento por acercarse a la izquierda peronista. Con este fin, se entrevistan con cuadros políticos de montoneros y con diputados de la tendencia y empiezan a participar de las concentraciones y manifestaciones, intentando presentarse como parte integrante del continuum identificado como "pueblo oprimido". Con este objetivo, concurrieron a la concentración organizada para festejar la asunción de Cámpora con una pancarta que decía "Los putos con Perón". Además, ese año, participaron con una columna de la masiva marcha a Ezeiza que recibe a Perón el 20 de junio, con una pancarta que resumía una estrofa de la marcha peronista: "Para que reine en el pueblo el amor y la igualdad". Solo dos meses después, asistieron a la marcha por el aniversario de la masacre del Trelew, el 22 de agosto, y a las concentraciones en repudio al derrocamiento de Salvador Allende, en Chile, en septiembre de ese año. ${ }^{4}$

Las consignas llevadas a las manifestaciones muestran la decisión de reivindicar la tradición peronista, en este intento de presentarse como parte integrante del abanico del campo popular. Nuevamente, este mensaje es plasmado también en las entrevistas que ofrecen a los medios de comunicación. Como por ejemplo en $A s i, 5$ una de las revistas populares de mayor tirada del momento, en la cual abandonan el lenguaje y la estética asociada a la tradición de los grupos guerrilleros marxistas, que había caracterizado a la entrevista anterior, para asumir una estética y un lenguaje ligado a la izquierda peronista: el informe -realizado en ocasión de la participación del Frente en la marcha a Ezeiza- señala que los activistas del Frente "mezclados con el pueblo peronista, sumaron sus consignas a los preceptos de lucha del conjunto". ${ }^{6}$ Los entrevistados, además, citarán a Evita y señalarán que la liberación sexual solo se da en el marco de la liberación nacional. Uno pocos meses más tarde, en una solicitada publicada en la tapa del mismo diario, se llamará a votar por Perón, a quien caracterizarán como la única opción popular y anti-imperialista.?

En este período, la obsesión por seducir a la izquierda peronista también quedará en evidencia en la prensa de la organización. El periódico Homosexuales ${ }^{8}$ publicado en julio de 1973, no parece estar destinado a las bases de homosexuales sino a presentarse ante las organizaciones de izquierda peronista. El periódico -repartido entre diputados y senadores progresistas, funcionarios estatales y militantes- efectuaba un explícito guiño al peronismo: se incluía en él un volante repartido en la marcha a Ezeiza con la ya mencionada cita de Evita, se celebraba el triunfo electoral de Cámpora y se reproducían cartas enviadas a distintas reparticiones estatales.

Sin embargo, esta apuesta al peronismo no estuvo exenta de tensiones al interior del Frente. En ese sentido, Perlongher señala que la radicalización del Frente espanta a los homosexuales burgueses y lo configura como una organización mayoritariamente de homosexuales de clases medias y bajas (Perlongher, 1997). También en una carta enviada en 1975 por un activista del FLH al periódico italiano Il Fuori, se consigna la aparición en Tucumán de un grupo de homosexuales que se autoproclamaba "procapitalista" y que criticaba al FLH por ser demasiado radical. ${ }^{9}$ Como ocurrirá en Brasil, la apuesta a la izquierda provocará el rechazo de quienes priorizaban la construcción interna y no necesariamente comulgaban con las organizaciones armadas.

Al interior del frente, los principales conflictos se generaron entre los grupos Eros y Profesionales. Este último -que junto a "Nuestro Mundo" había fundado el frente en 1971 y tenido un lugar principal en el diseño de su línea política-, empieza a ser severamente cuestionado en 1972 con el ingreso de Perlongher y los demás integrantes 
del grupo Eros, mayoritariamente conformado por jóvenes estudiantes de humanidades, muy ligados a la militancia en los centros de estudiantes y a los partidos de izquierda. Estas tensiones se acrecientan en 1973 con la escalada de la efervescencia social y el coqueteo con las organizaciones y estalla en las discusiones acerca de la participación en la marcha a Ezeiza, la cual termina con la salida del grupo de Sebreli.

Como vemos, la identificación con la izquierda no estaba exenta de tensiones. Sin embargo, el funcionamiento federativo en células autónomas permitió que el Frente pudiera contener a un amplio universo de activistas provenientes de trayectorias políticas y de tradiciones ideológicas diferentes -y hasta incompatibles-congregados en la lucha contra la represión policial. Por otro lado, la continuidad de la represión y las limitaciones para efectuar reuniones, hicieron que las discusiones operativas se efectuasen entre pequeños grupos de amigos, lo que limitaba la emergencia de conflictos.

Hubo algunas reuniones entre representantes de diferentes células, pero -por ejemplo- nunca llegó a haber una reunión plenaria en la que se concentrasen todos los miembros del frente. En Brasil, el primer congreso de activistas de todos los espacios homosexuales conglomera a más de 200 activistas de diferentes agrupaciones, y en él, las discusiones entre las perspectivas radicales y autonomistas fracturan el movimiento. En Argentina, el contacto entre las diferentes células era circunstancial y fortuito en fiestas y reuniones, o en encuentros limitados de unos pocos miembros en bares o casas particulares. No existió un territorio compartido para la discusión que posibilitase la emergencia de diferencias.

Sin embargo, a pesar de la heterogeneidad del Frente, que contenía a militantes de un amplísimo abanico de posiciones ideológicas, las de izquierda eran hegemónicas, lo que frecuentemente planteaba dificultades con el trabajo en las bases. El discurso de seducción dirigido a las organizaciones populares -que se plasmaba por ejemplo en las entrevistas dadas a la prensa masiva- alternaba sofisticados análisis teóricos basados en el freudo-marxismo con arengas en las cuales se convocaba a luchar por la liberación nacional. Pero este discurso, atractivo para los militantes de las organizaciones, caía muchas veces en la trampa de resultar extraño a las bases de homosexuales. A muchas de las "maricas", la mayoría de las cuales no estaban politizadas ni tenían una base intelectual que les permitiera decodificar las entrevistas, el mensaje les resultaba críptico y ajeno.

Hacia fines de 1973, los activistas veían defraudada su confianza en el régimen peronista al tiempo que este viraba hacia el neo-fascismo, desencadenando la persecución y el terror. Durante estos años, el frente empieza a tener cada vez menos activistas y más dificultades para encontrarse, producto de la persecución policial. Finalmente, en marzo de 1976 con el golpe militar, dejan de reunirse y varios militantes deben exiliarse.

\section{Las posiciones de la izquierda argentina frente a la sexualidad}

Es complicado efectuar un balance de la historia del Frente. Si bien incidieron positivamente en la concientización política de cientos de homosexuales y lograron intervenir por primera vez y en primera persona en los medios masivos de comunicación con un discurso reivindicatorio, uno de sus principales objetivos, la articulación con la izquierda argentina, quedo trunco, ya que estas jamás evaluaron una alianza con el movimiento homosexual, de escaso poder de convocatoria e importancia nula en el tablero político local. 
10. Ver: Dossier "Izquierda y homofobia" en Revista Lucha Armada en Argentina. Octubre 2014 / Agosto 2015.
La relación con el peronismo, al igual que con la izquierda en general, estuvo plagada de contradicciones. Cercana a la posición de la derecha conservadora, que identificaba a la homosexualidad como una degeneración, instrumento de la subversión para avasallar la masculinidad de occidente, una parte importante de la izquierda veía en el homosexual una aberración contrarrevolucionaria producto de la degradación moral de las últimas etapas del capitalismo, que desaparecería en la sociedad liberada junto con el hambre, la desocupación y el analfabetismo. ${ }^{10}$

Es necesario explorar con mayor profundidad la experiencia concreta de los militantes homosexuales en las organizaciones de izquierda de los setenta, sin embargo, las referencias con las que contamos dan cuenta de un ambiente opresivo. Anabitarte y otros militantes homosexuales del Partido Comunista son expulsados o enviados al psiquiatra (Anabitarte, 2005) y la Juventud Peronista les plantea abiertamente a miembros del FLH la posibilidad de internarlos en campos de reeducación una vez tomado el poder.

En las organizaciones armadas, la sexualidad fue un terreno de conflictos, intensificados por la gran heterogeneidad socio-cultural de sus activistas. Paralelamente, existían muchas tensiones entre la moral oficial y las prácticas concretas de los activistas que muchas veces la subvertían (Cosse, 2014).

A pesar de haber sido sumamente heterogéneo, en el peronismo predomino una política machista y homofóbica que puede rastrearse hasta la década del cuarenta. Por un lado, su imaginario tenía un fuerte anclaje en la masculinidad y en cierta noción de familia: el liderazgo político se construyo en base a una alegoría paternal, según la cual Perón es a la nación lo que el padre es a la familia (James, 2010). Por otro lado, la familia peronista -diseñada como uno de los pilares del régimen- se delinea en contraposición a la figura del amoral, que empieza a ser representado como el otro del régimen y de la nación y violentamente perseguido. En este marco, la homosexualidad es utilizada para denostar al contrincante político. Durante el conflicto con la iglesia, esta es acusada de promover la perversión sexual, al tiempo que para fogonear la inculpación, se promueve desde el Estado un pánico sexual en la prensa y se desencadenan las grandes razias de 1954, que terminan con cientos de homosexuales detenidos (Acha y Ben, 2004).

Sin embargo, hay que destacar las tensiones dentro de este movimiento sumamente complejo. El peronismo también impulsó el voto femenino y dictó la equiparación legal de hijos legítimos e ilegítimos, a la vez que fue pionero en propiciar la participación política de las mujeres a partir del Partido Peronista Femenino (1949-1955). Por otro lado, la promoción de la solidaridad obrera en los sindicatos peronistas estaba fundada en una fraternidad simbólicamente masculinizada, la cual, si bien tenía al amoral como su otro, también implicaba cierto grado de homoerotismo sublimado. Por ejemplo, Omar Acha (2014) analiza cómo en el deseo homoerótico en el marco de las hinchadas de fútbol se proyecta el deseo político y erótico de las bases por Perón.

Esta ambivalencia puede también encontrarse en las décadas subsiguientes. En los setentas, los discursos de Perón definían a la familia como pilar de la sociedad e interpelaban a la mujer como madre y ama de casa, en consonancia con políticas natalistas como la restricción del acceso a anticonceptivos (Felitti, 2012). Pero paralelamente, Montoneros, organizaba el movimiento "Evita" para organizar su frente femenino, el cual si bien reproducía los mandatos hegemónicos atribuidos a las mujeres y no se proponía problematizar su lugar en la estructura de la organización, sí favorecía una problematización de las relaciones de pareja, del lugar de la familia y de la violencia sufrida en los espacios de militancia que escapaba al control de las cúpulas (Grammático, 2012). Sin embargo, dada la retórica homofóbica dentro de la política 
peronista resultaba muy difícil que las organizaciones peronistas pudieran apoyar a un grupo de activistas homosexuales.

Respecto al PRT-ERP y a las demás organizaciones que adscribían al foquismo, inspiradas en la experiencia de la revolución cubana, el guevarismo fue uno de los principales escollos. El concepto de hombre nuevo desarrollado por Guevara (1977 [1965]) en El socialismo y el hombre en Cuba exigía una transformación moral del militante como paso previo a la redefinición de lo humano que tendría lugar en el socialismo. En esta transformación, los afectos de los activistas se volcarían progresivamente a lo colectivo, rechazando la propuesta individualista de la moral burguesa. El cambio moral era así inescindible del cambio social, y en este sentido, la vanguardia debía dar el ejemplo y demostrar que se podía ser coherente con el modo de vida revolucionario.

En Moral y proletarización el principal documento doctrinario del PRT-ERP sobre sexualidad, se indica que "una de las tareas de la revolución es la difusión de una moral de combate, una moral revolucionaria como etapa hacia una moral socialista" (Ortolani, 2004 [1972]). La moral burguesa debe ser combatida como vía a la construcción del hombre nuevo y la esfera de la intimidad no podía escindirse del compromiso político: la moral revolucionaria requería el control de las pasiones, habilitaba el escrutinio de la vida personal y favorecía la rigidez normativa. La sexualidad de los militantes se torna entonces objeto de una normativa que construye sujetos para la revolución (Oberti, 2015). Frente a esto, la sexualidad marica, representada como escandalosa y desmedida, era interpretada -al igual que el uso de drogas recreativascomo producto de un hedonismo burgués más centrado en el propio placer que en el compromiso colectivo. En esta línea, la izquierda armada promovía a la pareja militante la cual era definida exclusivamente en términos monógamos y heterosexuales.

Otros obstáculos para la incorporación de los homosexuales eran las performances de masculinidad prescriptas. En primer lugar, el ejemplo de virilidad de los combatientes "barbudos" de la revolución cubana, que había tenido como política de estado la deportación masiva de los pájaros a campos de trabajo forzado. En esta línea, Estrella roja, la prensa del PRT-ERP, exaltaba la virilidad de los guerrilleros -en un momento en el cual la derecha los representaba como afeminados y drogadictos- en línea con la masculinidad ideal representada por la figura del Che. Pero el Che, sin embargo encarnaba una masculinidad contradictoria: por un lado, representaba los ideales indisociables de masculinidad y valentía -ambas opuestas a la representación habitual de los homosexuales- pero por otro lado, su figura tenía un anclaje en la emotividad y en lo sensible que se plasmaba en lemas como "endurecerse sin perder la ternura" o que emergían en la reivindicación guevarista del amor revolucionario: "el revolucionario verdadero está guiado por grandes sentimientos de amor" (Guevara, 1965).

Esta férrea normativa (hetero)sexual prescripta desde las cúpulas, tenía sin embargo muchos puntos de fisura. En primer lugar, la presencia masiva de mujeres en las organizaciones armadas, si bien no necesariamente transformaron los roles de género al interior del movimiento, si pusieron en jaque al sujeto masculino de los partidos de izquierda revolucionaria (Oberti, 2015). Paralelamente, numerosos estudios dan cuenta de que estos espacios de militancia eran espacios de experimentación sexual que trasgredían las normativas sexuales de las organizaciones.

Por otro lado, en el caso del PRT-ERP hay notables casos de homosexuales militantes. Enrique Raab, secuestrado junto a su pareja por un grupo de tareas del ejército, llegó a ser director del órgano de prensa del partido, llamado - paradójicamente- Hombre Nuevo. Según Roberto Jacoby, entrevistado por María Moreno (Raab \& Moreno, 2015), la homosexualidad era considerada un tema privado, del cual ni siquiera se hablaba entre compañeros homosexuales. Moreno, sugiere que Raab rechaza pasar 
11. Radio de la Universidad de Rosario. Historia de amor dentro del horror: Entrevista Patricio Torne (23/03/2018). a la clandestinidad -lo que podría haber salvado su vida- ya que esto le hubiera significado exponer su intimidad y verse impedido de mantener cualquier tipo de contacto homosexual.

Patricio Torne, estuvo preso en Trelew por su militancia política en el PRT siendo apenas un adolescente entre 1975 y 1982. En la prisión, se enamora perdidamente de otro joven militante detenido, con quien inicia una relación que mantienen en secreto a los demás compañeros. Años después, en 1977, en un contexto en el cual la organización se había disuelto y sus principales líderes habían sido asesinados, deciden blanquear la relación con el resto de los compañeros, lo que Torne considera el peor error de su vida. Según él, "los compañeros estaban sumidos en un halo de prejuicios impuestos por la sociedad que aun ellos, autoproclamándose revolucionarios no podían superar" y no podían ver como "un estado de enamoramiento absoluto nos estaba salvando del delirio y de la crisis de la inmensa represión, de no saber cuándo te van a matar". ${ }^{11}$

El documental El silencio es un cuerpo que cae (Comedi, 2017) da cuenta de que, en estas organizaciones, participaban muchos homosexuales con mayor o menor nivel de visibilidad y de que, en algunos casos, activistas homosexuales de diferentes organizaciones armadas se reunían para debatir su situación al interior de las "orgas". Sin embargo, la moral revolucionaria devenía en un obstáculo tanto para la visibilidad de los homosexuales dentro de las organizaciones como para la incorporación de las agendas de estos al programa del partido.

Un caso particular dentro de las organizaciones revolucionarias lo constituye el trotskismo morenista. Según Sebreli (1997), el Partido Socialista de los Trabajadores (PST) es la única organización con la que el Frente logra una articulación provechosa. A expensas de un pacto secreto entre el FLH y Nahuel Moreno -el líder del partido- se le habilita al frente el uso de un mimeógrafo y de una habitación en un comité de Once, con la expresa condición de que nadie en el partido se enterase. Esta anécdota da cuenta de que si bien el PST no hizo público su apoyo a los homosexuales ni se propuso discutir el tema al interior del partido, sí existía una comprensión por parte de los dirigentes de que la lucha por la liberación sexual era una causa válida, aunque muy posiblemente evaluasen que aún no estaban dadas las condiciones para proponer una articulación semejante a las bases.

El principal escollo para la reivindicación de las luchas homosexuales por parte de los partidos trotskistas fue su carácter obrerista. Esta corriente definía al proletariado industrial como el sujeto político de la revolución por antonomasia, por lo que su estrategia privilegia era la orientación de las luchas en las fábricas mediante la inserción en sindicatos, comisiones internas y cuerpos de delegados. En este marco, la principal preocupación era que la incorporación de homosexuales dificultara el trabajo obrero.

Como señalamos en la introducción, Néstor Perlongher, por ejemplo, había abandonado la agrupación trotskista "Política obrera" porque -según sus ex compañeros-al "exhibir su condición de un modo transgresor" dificultaba la implantación del partido en el movimiento obrero que se llevaba a cabo mediante volanteadas en las fábricas y la participación y el apoyo a los obreros en los conflictos en sus lugares de trabajo (Gramar, 2017). En el recuerdo de Roberto Gramar, ex activista de "Palabra Obrera", la agrupación, si bien no priorizaba las demandas de los homosexuales tampoco condenaba a la homosexualidad. Sin embargo, sí se inquietaba ante la posibilidad de que la homosexualidad pública de alguno de sus activistas obstruyera el trabajo obrero. 
Sin embargo, a pesar de esto, el PST tenía ciertas características distintivas del resto de las agrupaciones de izquierda que lo colocaban en un lugar privilegiado para interpretar empáticamente las demandas de los homosexuales. Catalina Trebisacce (2015) describe una articulación con el movimiento feminista absolutamente novedosa en relación a las demás organizaciones de la época. A diferencia de otras agrupaciones de mujeres dentro de los partidos de izquierda como el movimiento "Evita" en Montoneros o el "Frente de Mujeres", en el PRT-ERP que estaban diseñados para la formación política de las mujeres, y no para el desarrollo de una política feminista, el PST engendró a "Muchacha", un grupo con relativa autonomía que abordó explícitamente la causa de la "liberación de la mujer" y generó fructíferos diálogos con el feminismo porteño.

Esto fue posible a partir de la incorporación de una novedad teórica: a diferencia del economicismo del resto de las organizaciones que reducía todos los conflictos a las lógicas de la opresión de clase, el PST, -influenciado por el feminismo socialista norteamericano a través de sus contactos con el Social Worker Party (SWP) de este país-interpretará la opresión de las mujeres en el entrecruzamiento de un doble sistema de opresión: el capitalista y el patriarcal. Esto, les permitirá estrechar lazos con las incipientes organizaciones feministas porteñas, a pesar de ser conscientes de que estas no abogaban necesariamente por una transformación radical en el modo de producción. Además, a diferencia de Montoneros o de PRT-ERP que consideraban al feminismo como una distracción burguesa, para el PST la liberación femenina era una herramienta válida para luchar contra el capital, y se comprometerán explícitamente con la causa a través de variedad de acciones. Según Trebisacce (2015), lecturas teóricas provenientes del feminismo y de la sexología circulaban aún entre los activistas que no tenían cercanía a "Muchacha". En 1972, el partido invita al país a Linda Jenness, la candidata a presidenta de Estados Unidos por el SWP, quien participa de charlas y eventos reivindicando la liberación femenina. $\mathrm{Al}$ año siguiente, postulan para las elecciones de 1973 la primera fórmula presidencial integrada por una mujer en la historia argentina, llevando como candidata a la vice-presidencia a Nora Ciaponni, quien hizo campaña enarbolando públicamente banderas feministas como la lucha por el derecho al aborto. Esta adscripción al feminismo fue de todos modos conflictiva, pero da cuenta de que el partido podía aprehender empáticamente vectores de la opresión no directamente ligados con la opresión de clase y considerados por el resto del arco de la izquierda como "demandas burguesas", lo que lo habilitaba a articular productivamente con agrupaciones policlasistas como las feministas u homosexuales. El modo en el cual el PST entendía el feminismo, evidenciaba que tanto sus desarrollos teóricos como el diseño de sus estrategias y tácticas políticas eran compatibles con la lucha de las minorías sexuales. De hecho, Moreno declarará que él y su partido están comprometidos a "luchar a muerte contra la opresión a los homosexuales" (Moreno, 1986) en 1986, mucho tiempo antes que el resto de los partidos progresistas.

Otro punto importante a considerar es el carácter internacionalista del trotskismo de aquellos años. Los partidos morenistas latinoamericanos no eran experiencias aisladas. Los partidos socialistas de los trabajadores, que florecieron en al menos una decena de países latinoamericanos tenían importantes conexiones desde el momento de su constitución. Los activistas viajaban permanentemente, los líderes participaban de los congresos de los demás partidos de la región, y muchos militantes eran orientados a desplazarse para fundar partidos en otros países. El morenismo pensaba sus estrategias a una escala global: se planificaba tácticamente en qué país fortalecer el partido y en cuál otro convenía en cambio desactivarlo. Como veremos luego, Convergencia Socialista -brazo legal del PST brasilero-surge a instancia de un grupo de activistas orientados por Moreno para desplazarse a Brasil a fundar un partido. Durante la dictadura argentina, los activistas aprovechan la necesidad de relocalizar a los activistas más expuestos para fortalecer los partidos de Bolivia, Chile, Ecuador, 
Costa Rica y Panamá y, el mismo Moreno, se traslada a Colombia, donde el PST local cobra una gran importancia.

Estos partidos, conformaban junto al SWP norteamericano y algunos otros europeos una corriente dentro de la cuarta internacional dirigida por Moreno que variará en sus nombres e integrantes desde mediados de los cincuenta y que se enfrentará a las opciones guerrilleras y foquistas en Latinoamérica. En esta corriente, será vital la asociación entre Moreno y el SWP, el partido trotskista más grande de Estados Unidos. El SWP es un caso interesante: según Sebreli (2011), fue la influencia de la SWP -que según él habría forjado una alianza con el "Gay Power"- lo que determinó que Nahuel Moreno se decidiera a amparar al FLH. Si bien hay constancias de que el SWP expulsó a sus miembros homosexuales al menos hasta 1970 (Phelps, 2013; Wolf, 2009), entre 1970 y 1973 el partido norteamericano emprende un debate interno de tres años sobre la naturaleza de la opresión homosexual y la postura hacia las organizaciones de homosexuales, en el cual participan miembros de diversas agrupaciones de liberación homosexual (Thorstad, 1976; Forgione et al., 1980). Aunque luego el debate haya sido clausurado por las cúpulas, optándose por defender los derechos civiles de los homosexuales y las lesbianas, a la vez que se mantenían distantes ante el movimiento, este proceso de debates internos demarcó a los colectivos homosexuales como interlocutores válidos en la lucha revolucionaria, y posiblemente haya dado la pauta a los partidos argentinos y brasileños de que la incorporación de los homosexuales era un tema a considerar.

\section{El movimiento de liberación homosexual brasileño}

Unos pocos meses después que el Frente argentino se desarticulase, comienzan los primeros intentos de organización en Brasil, que luego de un prolongado régimen autoritario empezaba lentamente a transicionar de los años de plomo-como se conoce a la etapa de mayor represión estatal- a una de mayor apertura política y cultural. El 4 de julio de 1976, un primer intento de reunión para conformar un congreso homosexual brasileño, que había sido publicitado en la prensa alternativa, es disuelto por la policía (Green, 1994). Sin embargo, poco tiempo después, surgen los primeros grupos clandestinos de discusión de la mano de João Trevisan, un activista brasileño, que había tenido contacto con el movimiento de liberación en San Francisco (Trevisan, 1986).

Es importante recalcar que, mientras que el deshielo de la Revolución Argentina y la primavera camporista que la siguió fueron breves y, enseguida, se vieron sucedidos por el incremento exponencial de la persecución de la extrema derecha durante el gobierno de Perón primero y por el autodenominado "Proceso de Reorganización Nacional" después, en Brasil la dinámica política fue diferente.

Mientras que la segunda mitad del siglo XX en Argentina estuvo caracterizada por una alternancia de breves períodos democráticos y dictatoriales, Brasil atraviesa un extenso régimen de facto que se extiende entre 1964 y 1985, pero que presenta características que la distinguen de la dictadura argentina.

La dictadura brasileña, que había nacido relativamente moderada en 1964 con el fin de acabar con la República Nova -de tinte progresista-, se vuelve extremadamente represiva en 1968 y particularmente en 1969 durante la presidencia de facto del General Garrastazu Medici (1969-1974), caracterizada por la violenta represión política y un férreo control de la prensa. 
A pesar de esto, el régimen logra un relativo apoyo social dado el espectacular crecimiento económico que caracterizó a Brasil de esos años que no puede sin embargo sobrevivir a la crisis del petróleo de 1973, que repercute severamente en la economía y mina el apoyo al régimen. Frente a esto el General Geisel (1974-1979), el presidente de facto siguiente, inicia un proceso gradual de democratización y apertura política que culminará con el llamado a elecciones libres recién diez años después. Tímidamente vuelve el activismo de izquierda, los sindicatos empiezan a recobrar fuerza y la resistencia popular contra la dictadura se reorganiza (Skidmore, 2009).

Es interesante el paralelismo: así como el FLH había cobrado fuerza durante la decadencia de la Revolución Argentina y el incremento de la resistencia popular acontecidos durante el gobierno de Lanusse, el activismo homosexual brasileño surge en el marco del deshielo de la dictadura brasileña, en un momento en el cual la resistencia obrera y estudiantil empezaban a recuperar fuerzas. Los movimientos homosexuales son parte indisociable de la nueva izquierda y como tales emergen, crecen y se retrotraen en sintonía con esta. En Brasil, en este clima de novedosa efervescencia militante, aparecerán Lampião da esquina ${ }^{12}$ y "Núcleo de Ação pelos direitos dos homossexuais", respectivamente el primer periódico y la primera organización homosexuales brasileñas. Pero, a diferencia de Argentina, donde el fortalecimiento de la nueva izquierda es rápidamente desmantelado por el retorno de los regímenes autoritarios, en Brasil, se inicia una lenta transición a la democracia que permitirá al movimiento homosexual crecer a una escala no vista hasta ese momento en Latinoamérica y propiciará una articulación novedosa e impensada con las bases y con el resto de los movimientos sociales del período. Sin embargo, habilitará también la emergencia de tensiones y conflictos que, en el caso de Argentina, el aislamiento y la represión habían contenido y difuminado.

\section{La emergencia del activismo homosexual}

En marzo de 1978 en San Pablo nace el "Núcleo de Ação pelos direitos dos homossexuais" grupo que evolucionará hasta ser uno de los más importantes del movimiento homosexual brasileño. En 1979, una nueva agrupación de izquierda proyecta una serie de discusiones con los movimientos sociales brasileños en la Universidad de San Pablo (USP) y reserva una de estas al movimiento homosexual. Este evento constituye la presentación pública del grupo, que decide estratégicamente cambiar su nombre a "Somos: Grupo de afirmação homosexual" en homenaje al Frente de Liberación Homosexual argentino y su publicación homónima. El movimiento brasileño tenía relación con ex miembros del FLH exiliados en San Pablo y estaba interesado en la experiencia y los materiales del frente (Green, 1994).

El grupo, que había sido conformado por una decena de integrantes al momento de su constitución, crecerá a lo largo de 1978 y más en 1979, luego de que los debates en la USP popularizan a la agrupación. Será entonces que activistas ligados a la izquierda -y principalmente a la agrupación trotskista Convergencia Socialista-ingresarán a la agrupación y empezarán a confrontar con los miembros fundadores, los cuales pugnaban por un movimiento de tinte "autonomista" lejos de la tradición del activismo de izquierda de articulación con el resto de los movimientos sociales en lucha contra la dictadura. Estas tensiones entre autonomistas y radicales dará lugar a dos facciones al interior del movimiento homosexual (Figari, 2009). Las perspectivas de estos dos grupos quedaron plasmadas en las investigaciones de João Trevisan $(1986,2018)$ y de James Green (1994, 2010, 2013, 2014, 2018), importantes líderes del movimiento en aquel periodo. Enfrentadas pero complementarias, estas exigen ser leídas en conjunto.
12. En 1977, Winston Leyland -un editor norteamericano- se reúne en Brasil con varios intelectuales rays para editar una compilación de literatura homófila latinpilación de De estas reuniones, sale la idea de editar el“"Lampião da esquina un periódico que plasmaría los principales debates del movimiento durante los años siguientes. 
Los activistas de izquierda empiezan a militar activamente dentro de "Somos" para que este grupo adquiera una orientación más activista y se involucre plenamente en los conflictos obreros y en la resistencia contra la dictadura. Simultáneamente, estos mismos militantes trabajarán en la agrupación trotskista Convergencia Socialista para que esta se incorpore plenamente a la lucha contra la opresión sexual.

Rápidamente triunfan en este objetivo. En 1978, Convergencia incorpora públicamente en su plataforma la defensa de los derechos de los homosexuales, convirtiéndose en la primera organización de izquierda brasileña (y posiblemente latinoamericana) en hacer pública una defensa de este tipo. En marzo de 1979, los activistas homosexuales deciden generar su propio espacio dentro del grupo y organizan la "Facción Homosexual de Convergencia Socialista" al tiempo que siguen presionando dentro de "Somos" para que esta articule con el resto de los sectores sociales en lucha contra la dictadura (Green, 2013).

\section{Género y sexualidad en la izquierda brasileña}

Cuando Convergencia Socialista decide incorporar la agenda homosexual a su programa, tanto el trotskismo como la izquierda se encontraban en un momento muy diferente a aquel en el cual el FLH argentino empezó sus primeros intentos de acercamiento en 1973. Al interior del trotskismo, por un lado, para 1978 hacía varios años ya que la SWP había iniciado discusiones internas sobre el tema. Por otro lado, con respecto a la izquierda brasilera, esta estaba atravesando un proceso de transformación íntimamente asociado a los profundos cambios económicos y políticos del periodo.

La izquierda brasileña sufre una primera reorganización a principios de la década del sesenta. El Partido Comunista ligado a la URSS que había hegemonizado la izquierda brasileña hasta ese momento -y que ya había sufrido la escisión de los grupos maoístas en 1962- acelera su diáspora cuando un gran número de sus activistas abandona sus filas para abrazar las organizaciones foquistas y los caminos cubanos al socialismo, descontentos con la tibia respuesta del PC a la dictadura. Sin embargo, tanto los partidos comunistas pro-soviéticos como los maoístas y los grupos de guerrilleros pro-cubanos seguirán la línea del comunismo internacional sobre la homosexualidad que ya hemos descripto, dándole a esta un contenido de clase y ligándola a la burguesía y a la reacción.

Según James Green (2012), esta posición resultó de la articulación de 5 marcos ideológicos - presentes tanto en el sentido común reaccionario como en las tradiciones de izquierda- que también podemos vislumbrar operando en las representaciones de la izquierda argentina. Por un lado, se asociaba la homosexualidad a las costumbres sexuales de la burguesía y, por tanto, a la contrarrevolución. Por otro lado, siguiendo los postulados de la medicina higienista, era considerada una degeneración física y por tanto, una condición patológica. Además, siguiendo los lineamientos de la iglesia, que tenía conexión con muchos grupos a partir de la teología de la liberación y que habían tenido influencia en la educación escolar de muchos militantes, consideraban la homosexualidad como una inmoralidad. Luego, en el marco del sentimiento anti-imperialista que ordenaba -al igual que en Argentina- el modo de entender el antagonismo político de algunos grupos, asociaban tanto a la homosexualidad como al activismo homófilo con las influencias intervencionistas norteamericanas. Finalmente, como ya describimos también para Argentina, la homosexualidad desplazaba las representaciones de la masculinidad revolucionaria, importante pilar de la identidad militante. 
Además, estas representaciones homofóbicas tradicionales no se problematizaban ni complejizaban a la par del resto de la sociedad brasileña que, ligado al boom económico desde fines de los sesentas, estaba atravesando un proceso de cuestionamiento de los roles tradicionales de género ligado al empoderamiento de las mujeres, que ahora accedían masivamente al trabajo en el marco del pleno empleo.

El aislamiento de la izquierda revolucionaria -muchas veces en la clandestinidad y concentrada en la supervivencia-impedía estas discusiones y en la mayoría de los casos, las transformaciones que estaba atravesando la sociedad brasileña eran signadas uniformemente como producto de la degradación capitalista: claudicar y abandonar la lucha (desbundar) era frecuentemente entendido como sinónimo de abrazar un estilo de vida ligado a Estados Unidos y a un individualismo reaccionario caracterizado por el uso de drogas, la música rock, la homosexualidad y la vida sexual promiscua (Green, 2012).

Como en Argentina, sin embargo, encontramos ciertos puntos de desplazamiento. La novedosa presencia de mujeres en las organizaciones armadas brasileñas, también implicó una tensión entre la relativa reformulación de los roles de género tradicionales que implicaba la figura de la combatiente mujer con las continuidades en estos roles en el marco de organizaciones que muchas veces solo reconocían la igualdad entre los géneros en términos retóricos, limitando a veces el ascenso de las mujeres en las estructuras partidarias. Pero, por otro lado, a diferencia de Argentina, el movimiento feminista brasileño surge en los setentas como reacción a la dictadura militar y, por tanto, articulado con las organizaciones marxistas clandestinas de la época, lo que posibilita un diálogo más fecundo que termina rindiendo sus frutos (Andersen Sarti, 2004).

A partir de 1974, los últimos remanentes de la lucha armada son aplastados y los activistas que habían pertenecido a las organizaciones armadas emprenden en la cárcel o en el exilio un proceso de discusión y auto-crítica de la experiencia de la insurgencia armada y en este marco, problematizan en algunos casos el papel de mujeres y homosexuales en la revolución.

Respecto a las mujeres, a partir de la visibilidad que ganó el tema luego de la declaración del año mundial de la mujer por parte de la ONU en 1975 y de la apertura política a partir de 1978 , las organizaciones feministas se visibilizan. Simultáneamente, la mayoría de las agrupaciones de izquierda que, a fines de la década del sesenta, habían considerado al feminismo como una desviación burguesa, empiezan a incorporar a sus programas la defensa de los derechos de las mujeres (Andersen Sarti, 2004). En un entorno más abierto políticamente, también surgieron nuevos movimientos sociales feministas, gais y afrobrasileños que empezaron a interpelar a los partidos de izquierda desde perspectivas novedosas. En este marco, para 1978, la izquierda brasileña se encuentra en una posición muy diferente a la que había primado a fines de los sesentas para intentar una articulación con los movimientos de diversidad sexual.

\section{La Facción Homosexual de Convergencia Socialista}

En este marco, la historia de la FHCS es interesante ya que constituye el primer ensayo exitoso de articulación entre el movimiento homosexual y la izquierda partidaria en Latinoamérica. Convergencia socialista -originalmente llamada "Liga Operaria"- tiene desde sus orígenes una fuerte ligazón con el morenismo argentino. Un grupo de exiliados brasileños exiliados en Chile escapan a Argentina luego del golpe de Pinochet y comienzan a militar en el PST, donde son orientados por Moreno para regresar a 
Brasil y construir el partido. Este primer grupo, crecerá en las universidades y, en 1976, enviará a los estudiantes a proletarizarse y militar activamente en las fábricas. Esta estrategia dará resultado y en 1977 empiezan a crecer en los cordones fabriles del $\mathrm{ABC}$ paulista y a tener presencia en los sindicatos, llegando a ser más de 800 personas.

En 1978, la Liga Operaria organiza su primer congreso nacional con la presencia de Moreno y enviados de otros países latinoamericanos y decide fundar dos partidos: el Partido Socialista de los Trabajadores (PST) como partido clandestino y Convergencia Socialista como su frente público y legal, con el fin de participar en la vida política brasilera que empezaba progresivamente a abrirse. A diferencia de lo que ocurrió en el morenismo argentino, Convergencia rápidamente tendría un lugar central en la organización del movimiento homosexual brasileño.

$\mathrm{Al}$ igual que en los ya descriptos casos del PST argentino y de la SWP, los dirigentes de Convergencia, si bien no eran decididamente homofóbicos, también temían que reivindicar la lucha homosexual los alienara de las clases trabajadoras y obturara el trabajo con las bases obreras. Sin embargo, una cuestión coyuntural generó una oportunidad política. En 1978, días después del congreso nacional, la cúpula entera del partido es detenida y la organización, vulnerable, entra en crisis. Cuando los líderes del partido son liberados en 1979, el partido está desorientado y en vías de reorganización. En este contexto, los homosexuales aprovechan y plantean la necesidad de fundar la FHCS, moción que es aprobada en medio de la confusión de tendencias y facciones enfrentadas.

La noticia de que Convergencia Socialista era el primer partido en incorporar la defensa de los homosexuales se expande y la facción crece rápidamente. A partir de 1980, la facción va a dirigir movimientos de estudiantes de colegios secundarios y va a ganar a muchos jóvenes llegando a tener hasta veinticinco personas, un número significativo considerando que se trataba de una organización que tuvo entre 400 y 800 miembros.

La FHCS proponía intervenir en tres ámbitos: al interior del partido, entre las bases de trabajadores y en el movimiento homosexual.

\section{$\mathrm{Al}$ interior del movimiento}

Desde el principio, el modo en el cual la FHCS se organizó en relación a la estructura partidaria facilitó el trabajo al interior del partido. La figura de la "facción" no existía en la estructura del partido, organizada según el modelo leninista. Convergencia estaba organizada en células, que contaba cada una con un dirigente que, a su vez, participaba junto a otros nueve representantes de una regional que tenía por su parte un coordinador. La FHCS rompía con esta estructura y era en cierta medida "paralela": desde la facción -que reunía a miembros de distintas instancias del partido- se pretendía coordinar un trabajo interno para que cada miembro lleve al interior de su propia célula la problematización de la cuestión sexual.

Para facilitar esta labor, la primera tarea fue elaborar un documento que presentase desde el marxismo la asociación de la lucha por la liberación sexual con la lucha de clases. El documento, titulado Teses para libertação homossexual vio la luz en octubre de 1979 .

Se reconoce en el documento la influencia teórica del freudomarxismo que ya había nutrido el pensamiento teórico de los activistas argentinos. Siguiendo a Wilhelm 
Reich, sostendrán que la represión sexual es necesaria para la reproducción de trabajadores dóciles para la producción en el marco de la familia patriarcal, y explicarán la homofobia del proletariado, como un desplazamiento alienado de una ira de clase que debería estar orientada hacia la burguesía explotadora. Los homosexuales son lo opuesto a la familia patriarcal y a la moral burguesa y por lo tanto, son reprimidos por el sistema, al tiempo que la liberación sexual es, perse, anticapitalista.

A diferencia del FLH, Somos debe enfrentar a los sectores reformistas del movimiento por lo que se ven forzados a aceptar los avances en materia de derechos sexuales del primer mundo capitalista y a reconocer que "en ciertas circunstancias, es posible para la burguesía hacer ciertas concesiones". ${ }^{13}$ Sin embargo, denuncian que estas conquistas no pueden ser sino meramente temporarias. El documento reconoce que la mayor parte del movimiento homosexual pelea por derechos democráticos. Pero advierten que si la discriminación a los homosexuales fuese derrotada, la opresión continuaría, ya que la familia patriarcal y la sociedad de clases son indisociables.

La segunda edición de este texto, se edita ampliada en septiembre de 1980 con el fin de ser discutida en todas las esferas del partido. James Green señala que, antes de la fundación de la facción, "la cuestión homosexual no era más que un punto de su programa formalmente adoptado y nunca comprendido desde las bases hasta la dirección". ${ }^{14} \mathrm{El}$ trabajo general de la FHCS pretende generar un cambio general de actitud a partir de la discusión del documento con las bases del partido. El éxito en esta tarea es relativo. A pesar de que las consignas de la facción son rápidamente impulsadas por las cúpulas, estas no llegan a ser trabajadas intensivamente al interior del partido. Sin embargo, la estructura partidaria basada en el centralismo democrático según el modelo del ¿Qué Hacer? (Lenin, 2015 [1902]) en el cual las decisiones son tomadas por cuerpos elegidos democráticos, pero son vinculantes para todas las instancias del partido, favorecía la disciplina y la cohesión, aun alrededor de causas como la homosexual, que en otros contextos podrían haber suscitado incomodidades entre los obreros.

\section{Con las bases trabajadoras}

Es interesante notar la diferencia de registro en la interpelación que el FLH y la FHCS hacen a la izquierda partidaria. Mientras que el FLH, en su intento de incorporarse dentro de la tradición del peronismo se dirige al "pueblo", la FHCS encauzada ya dentro de la tradición obrerista del trotskismo, busca interpelar al movimiento obrero, presentándose ella misma como de "trabajadores homosexuales".

En el volante repartido en la marcha del 1 de mayo $^{15}$-por ejemplo- los activistas reivindican la unidad de clase como estrategia para reclamar a los sindicatos el cese de la discriminación. Según el volante, la marginación de los obreros homosexuales por parte de sus compañeros trabajadores es propiciada por la patronal como parte de una estrategia para frustrar la unidad de la clase obrera. Así, el movimiento pierde la participación de millones de trabajadores homosexuales. En este marco, hacen un llamado a la unidad de clase que es al mismo tiempo un llamado a terminar con la discriminación: "Estamos acá en cuanto trabajadores para luchar por la unidad de clase. En cuanto sigamos siendo discriminados por los compañeros esta unidad de clase contra el patrón no se podrá concretizar..16

El registro del FLH es muy diferente. Los activistas argentinos tienen como primera prioridad la construcción de alianzas, por lo que su interpelación va dirigida a las cúpulas y altos cuadros de los partidos con un discurso de alta sofisticación teórica.
13. FHCS, “Teses para libertação homossexual”, septiembre de 1980.

14. "A la dirección de la fracción bolchevique", 4 de diciembre de 1980.

15. Comissão de Homossexuais
pro 1 de mayo, "Contra interpro 1 de mayo, "Contra inter-
venção nos sindicatos de ABC"

16. Comissão de Homossexuais pro 1 de mayo, "Contra intervenção nos sindicatos de ABC" (Todas las traducciones son del autor). 
17. “La Familia", Somos 4, septiembre de 1974 .
En cambio los activistas de la FHCS, como ya han logrado esta articulación, pueden dedicar sus esfuerzos a trabajar al interior del partido y a concientizar a las masas obreras. Además, los miembros del FLH no tenían una estructura que les permitiese militar en los cordones industriales. Los activistas de la FHCS, en cambio, disponían del aparato del partido que les daba acceso a los obreros y a las fábricas.

Por otro lado, las lecturas del freudomarxismo de Perlongher y del grupo "Eros" le dan al FLH un signo involuntariamente anti-obrero. El FLH le habla a la clase obrera desde un lugar de "resentimiento": la masculinidad obrera, en el discurso del FLH, es indisociable de la represión y de la violencia que los hombres ejercen sobre mujeres y niños como modo de garantizar la reproducibilidad del capital en el marco de la familia.

Esta caracterización de la masculinidad obrera es omnipresente en la revista Somos del FLH. En una nota publicada por Perlongher -bajo el seudónimo Víctor Bosch-, se analiza a la familia como "una estructura de poder del varón sobre la mujer"17 inherentemente opresiva en cuanto constituye un aparato encargado de la reproducción ideológica del sistema. El artículo se ilustra con un dibujo infantil que plasma de modo elocuente la representación de esta masculinidad irredimible, en un barrio prototípicamente obrero (Fig. 1).

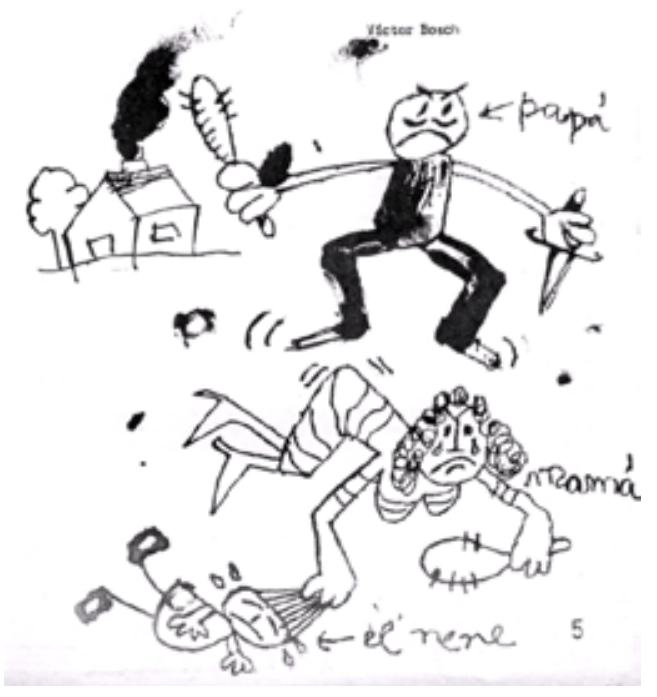

El freudomarxismo históricamente admitió usos anti obreristas: no se popularizó entre las bases, sino entre las elites intelectuales y estudiantiles, precisamente porque descorre a la clase obrera del lugar de sujeto natural de la revolución y pone el acento sobre la reproducción de la alienación que hay en sus prácticas. Que el FLH recupere la mirada del freudomarxismo - marginal en la izquierda argentina de los setentasexpone el aislamiento del FLH en el marco de la política argentina. Los activistas argentinos tienen que hacer un esfuerzo para construir una perspectiva teórica original porque ninguna de las que sostenía la izquierda argentina les reservaba un lugar.

En Brasil, la facción tenía una orientación mucho más pragmática y enfocada a la praxis política, con muchas menos lecturas teóricas que el grupo "Eros" -la usina intelectual del FLH-, el cual era básicamente un grupo de estudios compuestos por estudiantes de Filosofía y Letras. Por otro lado, el estar dentro de un partido obrero, influirá de modo determinante en su impronta y diluirá las tensiones que la masculinidad trabajadora generaba en el FLH. 


\section{En el movimiento homosexual}

Convergencia Socialista (CS) hacía un diagnóstico sobre el movimiento homosexual que ponía énfasis en las contradicciones de su carácter policlasista. Un balance interno, reconoce por ejemplo a las revueltas de Stonewall como efeméride fundacional, pero observan cómo su radicalidad fue rápidamente encauzada por una dirigencia pequeño-burguesa hacia un programa democratista. El documento señala como, en los países imperialistas, los movimientos son policlasistas en sus bases y pequeñoburgueses en su conducción, lo que influye negativamente en la concientización de millones de personas. Así, la mayoría de los grupos formados son direccionados por la pequeña burguesía, tienen un programa meramente democrático y no se involucran en las luchas obreras. ${ }^{18}$

La identificación frente al movimiento homosexual, vuelve a ser como en la interpelación a los obreros del ABC, como "trabajadores homosexuales": "Somos estudiantes secundarios, bancarios, universitarios, metalúrgicos y artistas. Mujeres y hombres que quieren llevar la cuestión de la discriminación no solo a los lugares que los homosexuales frecuentamos más, sino también a donde trabajamos y estudiamos, a nuestras organizaciones estudiantiles y nuestros sindicatos". ${ }^{19}$ El activismo no debía quedar enclaustrado en la cuestión homosexual, sino que debía desbordar hacia la articulación de las luchas contra la dictadura y el estado burgués. Este doble movimiento debía politizar a los homosexuales al tiempo que concientizaba al movimiento obrero sobre la necesidad de comprometerse con la revolución sexual.

La táctica de los activistas de CS era llevar dentro de Somos una política de orientación que implicaba participar en el espacio para orientarlo políticamente en una dirección: la alianza con el resto de los sectores oprimidos y la reivindicación de los sectores subalternos dentro de la agrupación. Frente al carácter policlasista del movimiento, la táctica era reforzar a la clase trabajadora y forzar una autonomización de los sectores burgueses: "El homosexual como cualquier movimiento policlasista tiene dos opciones: conciliación con la burguesía o independizarse del lado de los trabajadores. ${ }^{20}$

Los activistas de la FHCS empiezan así a aplicar dentro de Somos la línea tradicional de la izquierda para orientar movimientos sociales: en primer lugar, la búsqueda de alianzas con otros sectores oprimidos. Por ejemplo, en noviembre de 1979 los activistas de la FHCS proponen participar de una marcha junto con el "Movimiento negro unificado" para celebrar el "Día nacional de la conciencia negra" y protestar contra la discriminación racial. En otra oportunidad, cuando Lampião sufre un atentado, proponen solicitar la solidaridad de otros medios culturales, de izquierda y alternativos.

Estas iniciativas generaron reacciones dispares. La línea aplicada por la facción al interior de "Somos", termina resultando en la definición de dos posturas muy claras acerca de la definición de homosexualidad, del diagnóstico sobre la opresión social y de las estrategias a seguir. Una parte de Somos quería focalizarse en tareas de concientización siguiendo el modelo del feminismo, reflexionando sobre las propias experiencias en vistas al fortalecimiento de la comunidad gay. Otra parte, más política, pretendía una conceptualización más amplia y estructural de la opresión sexual y la articulación con otras minorías discriminadas y con el movimiento obrero (Figari, 2009).

La facción autonomista no estaba en contra de la necesidad de un cambio radical, pero la mayoría había tenido malas experiencias en organizaciones de izquierda y desconfiaba del centralismo y la verticalidad de los partidos tradicionales. En palabras de Trevisan, buscaban transformar la sociedad, pero a partir de acciones políticas
18. FHCS, "Trabalho homossexual: Um balanço e resolução de trabalho para o proximo ano", noviembre de 1981.

19. FHCS, “Nossos desafios", en: Boletim № 1, abril de 1981 .

20. FHCS, "Trabalho homosexual: Um balanço e resolução de trabalho para o proximo ano", noviembre de 1981. 
que "estuvieran profundamente enraizadas en sus vidas y lejos de cualquier comité central" (Trevisan, 1986). Consideraban el placer como un derecho inalienable, cuestionaban fuertemente los roles sexuales estereotipados y el modelo heterosexista de relacionamiento, así como investigaban el potencial transformador de la poligamia y reivindicaban la figura de la "loca". Creían a su vez, que la construcción colectiva y el autodescubrimiento eran un primer paso necesario para construir modos alternativos de luchar contra el sistema desde sus propias experiencias y, desde esta perspectiva, estaban en contra de toda forma de representación y liderazgo. En este marco, veían con muy malos ojos la influencia que Convergencia Socialista tenía sobre el grupo a través de algunos activistas que militaban en ambos espacios.

Los trotskistas, por otro lado, acusaban a los autonomistas de querer transformar al grupo en "un gueto de idealistas aislados de los conflictos reales" (Green, 2013) y priorizaban la necesidad urgente de una política de alianzas con el resto de los sectores en lucha contra la dictadura, pues la experiencia argentina los alertaba de que no había ninguna organización homosexual posible en un marco dictatorial.

En 1980, las diferencias al interior del movimiento homosexual estallan en el contexto de la intensificación de la lucha contra la dictadura. El primer congreso general de todos los grupos de homosexuales brasileños coincide con una serie de importantes huelgas obreras en los suburbios industriales de San Pablo y con la intervención del sindicato metalúrgico por parte del gobierno, hecho que exacerba la resistencia obrera.

La discusión acerca de si participar o no de la marcha del día de los trabajadores, que se pensaba como una gigantesca demostración de fuerzas del movimiento obrero para exigir el fin de la dictadura en respuesta a la intervención del sindicato metalúrgico, acapara las discusiones del congreso y dispara la división del grupo "Somos" y la retirada de los autonomistas.

En ese momento, se da una reestructuración en la estrategia del movimiento, que apuesta cada vez más fuerte a construir al interior del Partido de los Trabajadores (PT).

El PT había surgido en 1979 con la reforma de la ley de partidos políticos, que habilita el pluripartidismo en Brasil, y era liderado por Lula Da Silva, quien se había vuelto líder indiscutible de las huelgas metalmecánicas de San Pablo de los años 1978-1980. El PT, emerge conformado por un grupo heterogéneo de dirigentes sindicales, activistas e intelectuales de izquierda y adherentes al catolicismo tercermundista. Rápidamente se vuelve la opción política partidaria de amplios sectores populares que habían participado de las revueltas obreras paulistas de 1978-1980. Al mismo tiempo, empieza a incorporar activistas de otras fuerzas políticas, como los de Convergencia Socialista que devendrá una tendencia interna dentro del partido.

En 1981, un grupo de activistas gais del PT entre los que había varios miembros de Somos forma la comisión "Militantes homosexuales construyendo el Partido de los Trabajadores" (Green, 2004).

Unos meses después, en septiembre de 1981, Lula -quien había sostenido apenas dos años antes que no existían homosexuales en la clase obrera $-{ }^{21}$ declara en el segundo diario de mayor circulación de Brasil, que el PT no permitirá que la homosexualidad sea tratada como una enfermedad y que "defenderá el respeto que [los homosexuales] merecen, llamándolos a participar en la construcción de nuestra sociedad". ${ }^{22} \mathrm{Al}$ año de septiembre de 1981 . siguiente el PT incluye a ocho gais en sus listas para las elecciones legislativas de 1982, incluyendo a un activista homosexual que había salido públicamente del closet por televisión. Este cambio en las posiciones del PT no se explica únicamente por la influencia de los activistas homosexuales, de relativa influencia al nivel de las cúpulas 
del partido. Dan también cuenta de profundas transformaciones en la izquierda y el progresismo brasileros producto tanto de los cambios institucionales como de la entrada de una nueva generación de cuadros-de la mano de la emergencia de las nuevas contraculturas juveniles- y de la jerarquización de los nuevos movimientos sociales en el escenario de la izquierda (De La Dehesa, 2007).

Sin embargo, a pesar de haber logrado hacer realidad los sueños del FLH, consiguiendo articular con éxito con la política partidaria de izquierda, el movimiento de liberación brasileño entra en reflujo. Somos fue el primer, el más grande y el mejor organizado grupo gay de la época y, en cierta medida, era considerado vanguardia por el resto. Tanto Green (2013) como Trevisan (1986) coinciden en que las tensiones entre radicales y autonomistas desmoralizaron profundamente al movimiento entero y disminuyó considerablemente su capacidad de movilización colectiva.

En 1982 y 1983 , en todo Brasil, la movilización popular empieza a menguar en su conjunto. El movimiento obrero, que había perdido las grandes huelgas de 1980 ve como una parte importante de sus activistas se desmoviliza. El PT, la gran esperanza popular en las elecciones de 1982, obtiene un magro 8\% de los votos. Al mismo tiempo, una crisis económica sin precedentes golpea el país, y los activistas dejan de priorizar la militancia para dedicarse a la supervivencia económica.

Para 1983, a excepción del Grupo Gay Da Bahía todas las organizaciones que habían conformado el movimiento de liberación brasileño se habían disuelto.

\section{Conclusiones}

La historia del movimiento gay en general se ha construido en base a un supuesto internista que si bien reconoce que en sus inicios en los sesenta y setenta había una relación muy fuerte con la izquierda, esta relación aparece como un telón de fondo sin destacar su fuerza explicativa. Tanto en el caso del FLH como de Somos, las dinámicas de la articulación con los partidos de izquierda por un lado y los diferentes momentos políticos del estado por el otro son cruciales para entender su desarrollo.

En este sentido, la historia de los frentes de liberación homosexual latinoamericanos no puede entenderse si no se considera en relación a tres dimensiones. En primer lugar, en términos de las posibilidades y dificultades que existían para relacionarse con los diferentes actores de la izquierda, de la cual el Frente se consideraba parte. En consecuencia, en segundo lugar, en términos de las posiciones que las izquierdas adoptaban en torno a cuestiones de género y sexualidad y en relación a la capacidad que los diferentes partidos de la izquierda tenían para modificar sus posiciones y readecuarse, o no, a la emergencia de los homosexuales como un nuevo sujeto político en el campo progresista. Y finalmente, en relación al posicionamiento del Estado frente a ambos que, según el momento político, podía alternarse entre períodos de mayor represión que clausuraban la actividad política y, por tanto, la posibilidad del desarrollo de esta alianza o de relativa apertura, en el marco de las transiciones democráticas, que propiciaban un terreno para el diálogo y, en consecuencia, la incentivaban.

La política sexual y de género de las organizaciones juega un rol central para pensar tanto al movimiento de diversidad sexual como al campo de la nueva izquierda. Pero no puede entenderse si no es en el marco de estas tres cuestiones. Por ejemplo, ellas aportan una nueva perspectiva para pensar la razón por la cual el FLH no logra consumar su alianza con el PST y, en cambio, los homosexuales brasileros sí logran 
incidir en las cúpulas de Convergencia Socialista. Como ya hemos descrito, tanto el FLH y Somos en Brasil como el PST argentino y Convergencia Socialista eran agrupaciones que se pensaban en continuidad. En ninguno de ambos casos se trataba de políticas sexuales diferentes, ya que el programa teórico y político de ambos pares de agrupaciones eran similares. Sin embargo, en Brasil, el movimiento homosexual trabó relación con la izquierda en un contexto diferente, tanto en términos del momento global de la izquierda, como en relación al modo en el cual el Estado gestionaba el conflicto social.

En Brasil, a partir de 1974, el régimen de facto se enfrenta a una merma de su apoyo social producto de la crisis económica global y se ve forzado a iniciar un proceso paulatino de apertura, a diferencia de Argentina, donde el régimen de facto consigue controlar violentamente la disidencia política hasta su caída abrupta y sin concesiones en 1983. Este escenario diferencial le imprimirá al movimiento homosexual brasileño dos características distintivas. Por un lado, la temprana apertura -aun en los setentas- en conjunción con la intensificación de la insurgencia obrera, de la emergencia de la escena política y cultural alrededor de las universidades y la mayor libertad de reunión y asociación política generarán las condiciones para que el movimiento de liberación homosexual se desarrolle a una escala que fue inviable en Argentina.

Por otro lado, los partidos trotskistas tenían cierto grado de presión internacional para generar una apertura hacia los homosexuales. En algunos países del norte, la emergencia de un movimiento homosexual mucho más masivo a fines de los sesenta y principios de los setenta había conducido a toda una serie de conflictos que se resolvieron finalmente con la incorporación de la agenda gay al programa partidario trotskista. Luego de Stonewall, se forman cientos de grupos de activistas a lo largo de todo Estados Unidos, los cuales se nutren con militantes que habían roto con los partidos de izquierda por el rechazo de estos a incorporar la defensa de sus derechos a sus programas. Esta sangría de homosexuales de los partidos de izquierda -descripta por Martin Duberman (1994) en Stonewall-se plantea como un desafío a la izquierda, en el mismo momento en que otros grupos -asociados a lo que posteriormente serían llamados los "Nuevos movimientos sociales"- también generaban un éxodo masivo de militantes. El movimiento de mujeres, los movimientos pacifistas contra la guerra de Vietnam, los movimientos por los derechos civiles, planteaban nuevas agendas que hacían que los militantes transicionaran desde grupos de izquierda focalizados en la lucha de clases hacia grupos militantes con agendas políticas más particulares y vinculadas a identidades o temáticas nuevas.

En este marco, la izquierda de muchos países centrales reformula sus programas y comienza a apropiarse de estas demandas. Si bien en Argentina y Brasil estas agendas no surgen con la misma fuerza, la aceitada vinculación trasnacional de los trotskistas en el marco de las diversas fracciones de la cuarta internacional hace que estas líneas circulen y se discutan globalmente. En parte, el hecho de que en Brasil los homosexuales hayan logrado incidir en el trotskismo mientras que en Argentina no, está vinculado a los momentos de este entrelazamiento internacional: la interpelación al PST por parte de los homosexuales argentinos ocurre tempranamente, cuando aún el SWP estaba dedicado a la discusión del tema. Con los años, la agenda homosexual adquiere mayor legitimidad dentro del trotskismo internacional. Cuando los homosexuales brasileros plantean en 1978 la problemática homosexual al partido-liderados por un carismático homosexual norteamericano que era frecuentemente confundido con un enviado de la SWP- los colectivos homosexuales ya eran reconocidos como interlocutores válidos por la mayor parte del trotskismo global.

Un factor fundamental que posibilitó el acercamiento fue la propuesta teórica que aportaron los homosexuales. Como ya hemos desarrollado, ante la inexistencia de 
marcos teórico-políticos útiles para que estos primeros activistas homosexuales de izquierda pudieran dar cuenta de su opresión, estos militantes debieron recurrir a corrientes teóricas que no eran las que habitualmente circulaban en los espacios militantes. El freudomarxismo de Reich y Marcusse-que llevaba décadas circulando por los ámbitos académicos e intelectuales pero que no era hasta ese entonces una lectura frecuente en los partidos de izquierda- llega a los partidos de la mano de estos activistas y aporta una perspectiva novedosa para que los cuadros de los partidos interpreten la sujeción de los trabajadores a la ideología burguesa. A partir de estos textos, las cúpulas empiezan a sospechar, junto con Marcuse (1955) que quizá, la existencia de la homosexualidad era contradictora con la reproducción del capitalismo. La crítica que, a partir de "Eros y Civilización", los homosexuales harán a la familia patriarcal como institución encargada de reprimir la sexualidad no reproductiva en vistas a la reproducción de fuerza de trabajo disciplinada para el trabajo alienado, será compatible con el lugar que reserva a la familia como aparato reproductor de la fuerza de trabajo autores marxistas de tradiciones tan divergentes como Althusser (1970) y Engels (2007 [1884]) y que ya llevaba décadas presente en los documentos internos de las diversas organizaciones. ${ }^{23}$ Desde esta perspectiva, los cuadros teóricos del trotskismo posiblemente hayan sospechado que, acabar con la lógica de la familia heterosexual -tal cual proponían los homosexuales y las feministas- de alguna manera podía contribuir a producir sujetos más proclives a la concientización revolucionaria.

Nuevamente, sin entender la política de las izquierdas, los nudos internacionales, los momentos políticos y el lugar del Estado, no se puede comprender ni la evolución de la izquierda, ni sus cambios en cuanto a la cuestión de género y sexualidad. En muchas ocasiones, cuando se piensa la relación entre izquierda y movimiento homosexual, se lo hace únicamente en términos de analizar si los diferentes partidos o agrupaciones eran más o menos machistas u homofóbicas. Aquí planteamos una visión diferente: puede haber machismo y homofobia y, aun así -como es el caso del trotskismo-, una decisión centralizada, tomada por ciertos líderes, e impuesta a las bases a través del centralismo democrático, puede permitir la incorporación de una agenda de un modo inesperado. Desde el punto de vista que normalmente se adopta para estudiar esta cuestión, se equipararía el machismo y la homofobia con la imposibilidad de tejer alianzas y de incorporar la agenda homosexual. Sin embargo, la evidencia histórica muestra lo contrario: señala que la clave no está en la presencia o no de homofobia, sino en la forma en que, en determinados contextos históricos, la experimentación política creativa, el uso original de desarrollos teóricos desatendidos en contextos novedosos, y ciertos entrelazados políticos a nivel planetario podían generar presiones para incorporar -o no- agendas largamente resistidas.
23. Aunque en otro sentido, ya el Manifiesto Comunista (Marx, 1965 [1848]) exigía la abolición de la familia y de la explotación de los hijos por parte de los padres. 


\section{Q Bibliografía}

»Acha, Omar (2014). Crónica sentimental de la Argentina peronista: sexo, inconsciente e ideología, 1945-1955. Buenos Aires, Argentina: Prometeo.

"Acha, Omar y Ben, Pablo (2004). "La homosexualidad masculina durante el primer peronismo". Trabajos Y Comunicaciones, 30-31.

" Althusser, Louis (1970). Ideología y aparatos ideológicos de Estado. Bogotá, Colombia: Los comuneros.

»Anabitarte, Héctor (2005). Nadie olvida nada. Aranjuez, España: Ediciones Impublicables..

»Andersen Sarti, Cynthia (maio-agosto/2004). "O feminismo brasileiro desde os anos 1970: revisitando uma trajetória”. Estudos Feministas, vol. 12(2)(n-264), Florianópolis, UFSC.

"Bellucci, Mabel (2010). Orgullo. Buenos Aires, Argentina: Emecé.

" Ben, Pablo e Insausti, Santiago Joaquin (2017). "Dictatorial Rule and Sexual Politics in Argentina: The Case of the Frente de Liberación Homosexual, 1967-1976". Hispanic American Historical Review, vol. 97 (n²). Durham, Duke University Press.

» Maristany, Juan Carlos (Productor) y Comedi, Agustina (directora). (2017) El silencio es un cuerpo que cae [cinta cinematográfica]. Buenos Aires, Argentina: El Calefón.

"Cosse, Isabella, Infidelities (2014) "Morality, Revolution, and Sexuality in LeftWing Guerrilla Organizations in 1960s and 1970s Argentina". Journal of the History of Sexuality, vol. 23(3), Austin, University of Texas Press.

»De La Dehesa, Rafael (2007).“El sexo y la revolución:la liberación lésbico-gay y la izquierda partidaria en Brasil”. Revista de Estudios Sociales, vol. 28. Bogota, Universidad de los Andes.

»Duberman, Martin (1994). Stonewall. New York: Plume.

»Engels, Friedrich (2007). El origen de la familia, la propiedad privada y el Estado. México: Berbera.

» Felitti, Karina. (2012). La revolución de la píldora: Sexualidad y política en los sesenta. Buenos Aires, Argentina: Edhasa.

» Figari, Carlos (2009). Eróticas de la disidencia en América Latina. Buenos Aires, Argentina: CLACSO.

» Forgione, Steve y Thorstad, David (1980). No apologies: The unauthorized publication of internal discussion documents of the Socialist Workers Party (SWP) concerning lesbian/gay male liberation, New York, Estados Unidos: L/GRMG..

» Gramar, Roberto (23 de marzo de 2017) "PTS: cómo fabricar una calumnia", Prensa Obrera. Recuperado de https://prensaobrera.com/politicas/35995-ptscomo-fabricar-una-calumnia

»Green, James (2004). "Deseo y militancia: lesbianas, gays y el Partido de los Trabajadores de Brasil”. En P. Drucker (Comp.), Arcoiris Diferentes. Mexico: Siglo Veintiuno. 
" Green, James (1994) “The Emergence of the Brazilian Gay Liberation Movement, 1977-1981". Latin American Perspectives, vol. 21(1).

»Green, James 82010). “A luta pela igualdade: desejos, homossexualidade e a esquerda na América Latina”. Cadernos AEL, vol. 10(18/19).

"Green, James (Agosto 2012) "Who Is the Macho Who Wants to Kill Me?" Male Homosexuality, Revolutionary Masculinity, and the Brazilian Armed Struggle of the 1960s and 1970s", Hispanic American Historical Review, Vol. 92 (3).

"Green, James (2013) "Desire and Revolution: Socialists and the Brazilian Gay Liberation Movement in the 1970s", En J. Stiles Mor (Ed.), Human Rights and Transnational Solidarity in Cold War Latin America. Wisconsins, Estados Unidos: University of Wisconsin Press.

" Green, James (2014). “Abaixo a repressão, mais amor e mais tesão”: uma memória sobre a ditadura e o movimento de gays e lésbicas de São Paulo na época da abertura", Revista Acervo, vol. 27(1).

" Green, James (2018). "Forjando alianças e reconhecendo complexidades:as idéias e experiências pioneiras do Grupo Somos de São Paulo", En: História do Movimento LGBT no Brasil, São Paulo, Brasil: Alameda.

" Guevara, Ernesto (1977). El Socialismo y el hombre nuevo. México: Siglo Veintiuno.

»Insausti, Santiago Joaquin (2007). "Una mirada sobre las publicaciones del Frente de Liberación Homosexual", Actas de las IV Jornadas de Historia de las Izquierdas. Buenos Aires, Argentina: CEDINCl.

»Insausti, Santiago Joaquin (2019), "Una historia del Frente de Liberación Homosexual y la izquierda en Argentina", Revista Estudos Feministas, Florianopolis, Brasil: Universidad Federal de Santa Catarina. vol.27 no.2James, Daniel (2010). Resistencia e integración: El peronismo y la clase trabajadora argentina, 1946-1976. Buenos Aires, Argentina: Siglo Veintiuno Editores.

»Lenin, Uliánov llich (2015). ¿Qué hacer?. Madrid, España: Tres Cantos.

» Marcuse, Herbert (1955). Eros and civilization. Boston, Estados Unidos: The Beacon Press.

" Marx, Karl (1975). Fundamentos de la crítica de la economía. La Habana, Cuba: Edit. de Ciencias Sociales.

» Marx, Karl y Engels, Friedrich (1965). Manifiesto del Partido Comunista. Buenos Aires, Argentina: Anteo.

»Moreno, Nahuel (1986). Conversaciones con Nahuel Moreno. Buenos Aires, Argentina: Antídoto.

"Oberti, A. (2015). Las revolucionarias: Militancia, vida cotidiana y afectividad en los setenta. Buenos Aires, Argentina: Edhasa.

"Ortolani, Luis (1972). Moral y proletarización, Reproducido en Políticas de la Memoria $\mathrm{N}^{\circ} 5$, (2004/5) Buenos Aires, verano, [Originalmente publicado con el seudónimo Luis Parra en La gaviota blindada, $\mathrm{N}^{\circ} \mathrm{o}$, Rawson, Argentina].

»Perlongher, Nestor (1997), "Historia del Frente de Liberación Homosexual de la Argentina”. En Prosa plebeya. Buenos Aires, Argentina: Colihue.

»Phelps, Christopher (2013). "The Closet in the Party: The Young Socialist Alliance, the Socialist Workers Party, and Homosexuality, 1962-1970", Labor, vol. 10 ( $n \cong$. . 4).

"Raab, Enrique \& Moreno, Maria (2005). Periodismo todoterreno. Buenos Aires, Argentina: Sudamericana. 
"Rapisardi, Flavio \& Modarelli, Alejandro (2001). Fiestas, baños y exilios. Buenos Aires, Argentina: Sudamericana,.

»Sebreli, Juan Jose (1964). Buenos Aires, vida cotidiana y alienación. Buenos Aires, Argentina: Siglo Veinte.

"Sebreli, Juan José (1997). "Historia Secreta de los Homosexuales en Buenos Aires", En: Escritos sobre escritos, ciudades bajo ciudades. Buenos Aires, Sudamericana.

» Simonetto, Patricio (2017) “Movimientos de liberación homosexual en América Latina (1967-1982)", Iberoamericana, vol. 65, año XVII.

»Simonetto, Patricio (2017). Entre la injuria y la revolución. Quilmes, Argentina: UNQ.

"Skidmore, Thomas (2009). Brazil: Five Centuries of Change. New York, Estados Unidos: OUP.

»Trevisan, João (1986). Devassos no paraíso. São Paulo, Brasil: M. Limonad.

»Trevisan, João (2018). Somos o quê mesmo?. En: História do Movimento LGBT no Brasil. São Paulo, Brasil: Alameda.

» Thorstad, David (1976), Gay liberation and socialism: Documents from the discussions on gay liberation inside the Socialist Workers Party (1970-1973). New York, Estados Unidos: D. Thorstad.

"Trebisacce, Catalina y Mangiantini, Martin (septiembre de 2015), “Feminismo, diversidad sexual y relaciones sexo-afectivas disidentes. Apuestas y tensiones en el PST, 1971-1975. Archivos, no 7, año IV.

"Vespucci, Guido (2011). “Explorando un intrincado triángulo conceptual: homosexualidad, familia y liberación en los discursos del Frente de Liberación Homosexual de Argentina (FLH, 1971-1976)", Historia Crítica, nº 43,.

»Vespucci, Guido (2017). Homosexualidad, familia y revindicaciones: de la liberación sexual al matrimonio igualitario. Buenos Aires, Argentina: UNSAM.

"V.V.A.A, (2017/2015) Dossier “Izquierda y homofobia”, en: Revista Lucha Armada en Argentina, año 10.

»Wolf, Sherry (2009). Sexuality and Socialism: History, Politics, and Theory of LGBT Liberation. Chicago, Estados Unidos: Haymarket Books. 